\title{
Carcinoid tumour of stomach and primary hyperparathyroidism: a new association
}

\author{
J RODE,* A P DHILlON,§ P B COTTON, $\dagger$ A WOOLF, $\ddagger$ J L H O’RIORDAN $\ddagger$
}

From *The Bland-Sutton Institute of Pathology, Departments of $\dagger$ Gastroenterology and $\ddagger$ Medicine, The Middlesex Hospital and Medical School, and the §Department of Histopathology, Royal Free Hospital School $\vec{\phi}$ Medicine, London

SUMMARY Three cases of carcinoid tumour of the stomach associated with primary hypero parathyroidism had the clinical and pathological features of a pluriglandular syndrome. Two of the patients showed multiple small polypoid carcinoids in the non-antral stomach, in conjunction witgr a parathyroid adenoma in one and parathyroid hyperplasia in the other case. One of these patient $\$$ was also suffering from pernicious anaemia. A third patient had a large metastasising carcinoiф arising in the gastric body and a parathyroid adenoma. Immunohistochemical stains for PGP $9 \cdot 5$ were positive in the carcinoids of all three cases. In all cases the carcinoids showed immunoreactivit for gastrin. A positive family history of endocrine hyperplasia and neoplasia was established in on⿷ case.

It is suggested that patients with gastrointestinal carcinoids and their families should be evaluated for hyperparathyroidism, and patients with hyperparathyroidism presenting with upper gastro intestinal symptoms should undergo endoscopy to rule out gastric carcinoid tumours.

Multiple endocrine syndromes have aroused considerable interest since their recognition as familial disorders by Wermer in 1954. ${ }^{1}$ These conditions are characterised by adenomas, carcinomas, or hyperplasia affecting endocrine glands. The parathyroids, pancreatic islets, and pituitary are most commonly affected, followed by adrenals and thyroid. Carcinoid tumour of the lung, ${ }^{23}$ duodenum, ${ }^{45}$ ileum, ${ }^{6}$ and thymus ${ }^{7}$ have been reported in these patients, with a higher incidence than would be expected from mere chance.

We report three cases of carcinoid tumour of the stomach associated with primary hyperparathyroidism. To our knowledge this association has not been described previously.

\section{Case reports}

CASE 1

A 56 year old woman investigated for melaena and anaemia showed a corrected calcium concentration of $3.3 \mathrm{mmol} / \mathrm{l}$. Further tests showed that she had a raised

Accepted for publication 22 December 1986 alkaline phosphatase activity of $350 \mathrm{IU} / 1$, and sub\%ั periostal resorptions were seen on her hand $x$-ray Her pubic ramus showed an expanding bone lesior? on the left side. Endoscopic examination showed a hiatus hernia and mild oesophagitis. An umbilicate mass $(1 \mathrm{~cm})$ was seen at $45 \mathrm{~cm}$ on the posterior aspect. of the stomach close to the lesser curvature, an several small umbilicated and eroded polyps weré present scattered throughout the gastric body $\underset{3}{3}$. Peripheral venous gastrin was raised to $123 \mathrm{pmol} / \mathbb{B}$ (normal $=<55 \mathrm{pmol} / \mathrm{l}$ ) and pancreatic polypeptide to $841 \mathrm{pmol} / \mathrm{l}$ (normal $=300 \mathrm{pmol} / \mathrm{l}$ ). Ultrasound examination of the abdomen did not show any abnor malities. Subsequent exploration of the neck showede four enlarged parathyroid glands.

The patient's father had died of "carcinoma" of the stomach; her brother had died from a neuroendocrines tumour of the pancreas obstructing the common bilet duct and had also had renal stones and hypero calcaemia. Her niece had undergone an operation for parathyroid hyperplasia.

\section{CASE 2}

A 38 year old man presented with arthropathy and was found to be hypercalcaemic with calcium concen $\widetilde{\Omega}$ trations of $3.00 \mathrm{mmol} / \mathrm{l}$. His hypercalcaemia was not̄ suppressed with steroids and he had hypercalciuria 
Exploration of the neck showed an enlarged left lower parathyroid gland. No other parathyroid glands were identified. Three years postoperatively the patient became hypercalcaemic again, and parathyroid hormone values, as well as serum gastrin concentrations $(176 \mathrm{pmol} / \mathrm{l})$ were raised. Other gastrointestinal hormones were within normal limits.

At 48 years of age the patient presented with melaena. Endoscopic examination showed a large, ulcerated gastric polyp of the anterior wall of the lower body close to the lesser curve. A total gastrectomy and splenectomy was performed.

The patient's father had died of carcinoma of the bile duct; his mother suffers from diabetes mellitus and his brother from recurrent kidney stones.

\section{CASE 3}

A 48 year old woman developed pernicious anaemia. Endoscopic examination showed multiple gastric fundus and body polyps, the largest of which measured $0.8 \mathrm{~cm}$. The serum gastrin concentration was raised to $2030 \mathrm{pmol} / \mathrm{l}$ and pancreatic polypeptide to $270 \mathrm{pmol} / \mathrm{l}$.

When 50 years old a routine blood screen showed corrected calcium concentrations of $2.76 \mathrm{mmol} / \mathrm{l}$. The peripheral parathyroid hormone value was inappropriately raised and the patient was hypercalciuric. A nodular portion of thyroid gland was removed from its left lower lobe. Three other normal sized parathyroid glands were identified and biopsied. She remained normocalcaemic. She was followed up by endoscopy for seven years, and the gastric findings are unchanged at the time of writing. Her mother had pernicious anaemia and diabetes mellitus: her nonidentical twin sister is alive and well at the time of writing.

\section{Gross findings and histopathology}

\section{STOMACH}

Multiple biopsy specimens from the polyps and unaffected gastric body mucosa were available from cases 1 and 3. The gastrectomy specimen of case 2 showed a polyp measuring $2 \mathrm{~cm}$ in diameter and protruding $1.5 \mathrm{~cm}$ above the mucous surface of the lower body of the stomach. No other mucosal abnormalities were evident by naked eye inspection. Six lymph nodes were found at the lesser curve.

Sections were prepared from routinely formalin fixed and paraffin embedded material. Consecutive sections were stained with haematoxylin and eosin and an alcian blue-periodic acid Schiff diastase-lead haematoxylin sequence ${ }^{8}$ to show differentially acid and neutral mucins and neurosecretory granules. Indirect immunoperoxidase stains were performed for the general neural and neuroendocrine markers neurone specific enolase (NSE) and protein gene product $9 \cdot 5$ (PGP 9.5), ${ }^{9}$ gastrin, pancreatic polypeptide (PP), calcitonin, somatostatin, glucagon, and 5HT.

Haematoxylin and eosin sections of the polyps of all three cases showed gastric body mucosa infiltrated by carcinoid tumour composed of sheets (fig 1), islands, and typical trabeculae of tumour cells. Case 1 also showed conspicuous areas where the tumour exhibited a pseudoglandular pattern. In biopsy specimens of the larger polyps of cases 1 and 3 tumour was seen infiltrating through the muscularis mucosae into the superficial submucosa. The large tumour in case 2 expanded the submucosa and impinged on to the muscularis propria. Occasional tumour cell mitoses (1-2/high power field) were detected in this case alone. Metastatic tumour was found in three lymph nodes from the lesser curve close to the main tumour. Three more distant lymph nodes from the lesser curve were tumour free.

All cases showed chronic gastritis with small intestinal metaplasia. Case 3, with pernicious anaemia, showed severe mucosal atrophy with complete loss of specialised glands and pseudopyloric metaplasia. In all cases tumour cells containing lead-haematoxylin positive neurosecretory granules were shown.

Immunohistochemical stains for PGP 9.5 were positive in the tumours of all three cases (fig 2 ). This marker also showed small neuroendocrine cell proliferations in all cases within the deeper lamina propria of apparently unaffected body mucosa. These mucosal endocrine cell proliferations previously described by us ${ }^{10}$ were inconspicuous in haematoxylin and eosin sections. Tumour and mucosal endocrine cell proliferations expressed NSE in cases 2 and 3 but not in case 1 . In all three cases the tumours showed positive areas for gastrin (fig 3). PP positive tumour cells were shown in cases 1 (fig 4) and 3, commensurate with the raised blood concentrations of this hormone in these patients. Only case 3 showed occasional positive staining of tumour cells for substance $\mathrm{P}$ and $5 \mathrm{HT}$.

\section{PARATHYROID GLANDS}

In case 1 four enlarged parathyroid glands were removed during exploration of the neck. These ranged in weight from $162 \mathrm{mg}$ to $2.6 \mathrm{~g}$ (normal = $30 \mathrm{mg}$ ). Haematoxylin and eosin sections of each gland showed solid parathyroid tissue composed of chief cells and devoid of interspersed adipocytes. Nodular hyperplasia of parathyroid glands was therefore diagnosed.

In case 2 only one parathyroid gland was found at surgery. It was enlarged and weighed $0.5 \mathrm{~g}$. Histology showed solid parathyroid tissue composed of chief cells with a rim of compressed normal parathyroid in 


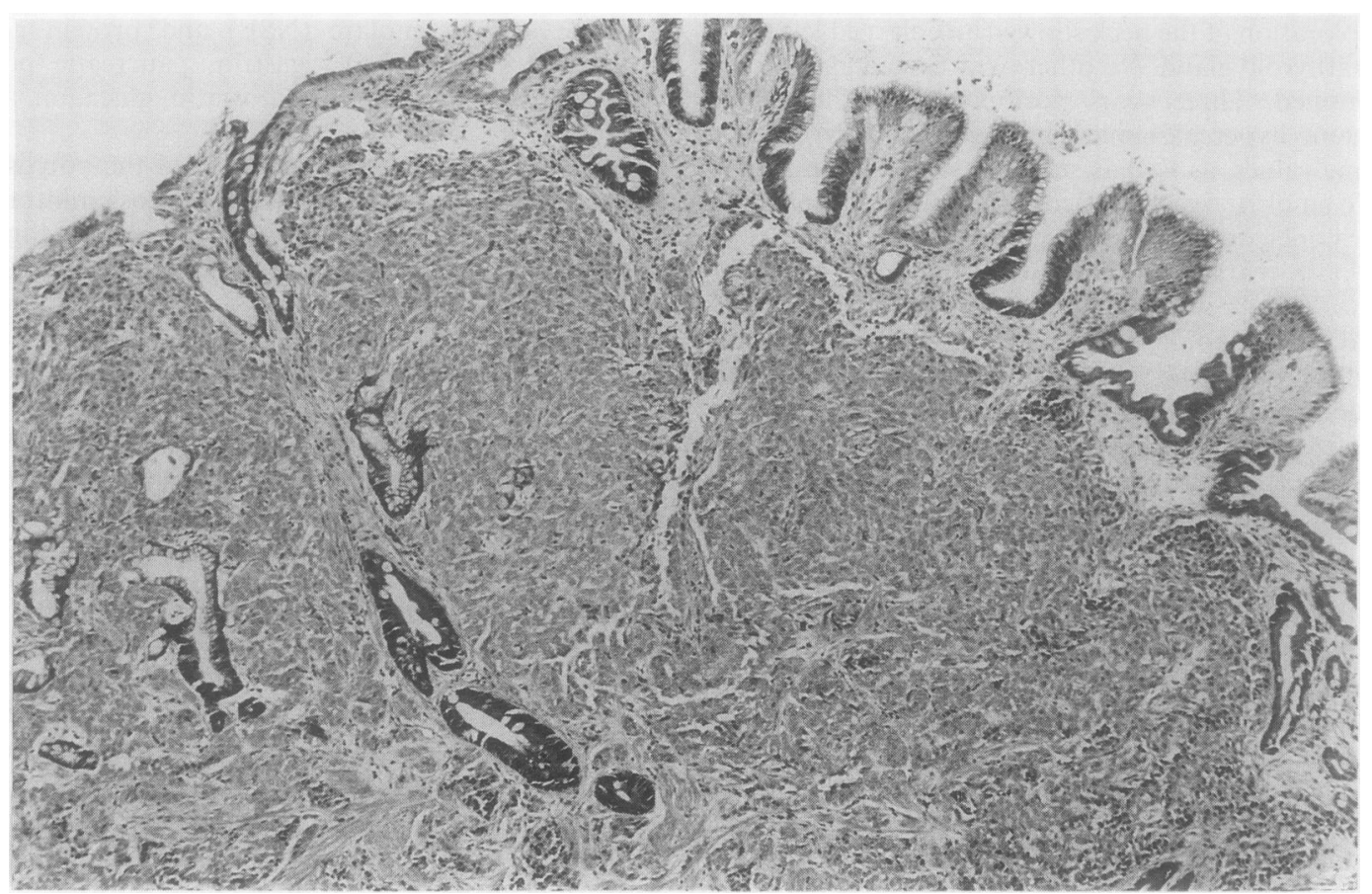

Fig 1 Endoscopic biopsy specimen of largest of multiple gastric body and fundic polyps in case 3 showing sheets of carcinoid tumour expanding lamina propira. (Haematoxylin and eosin.)

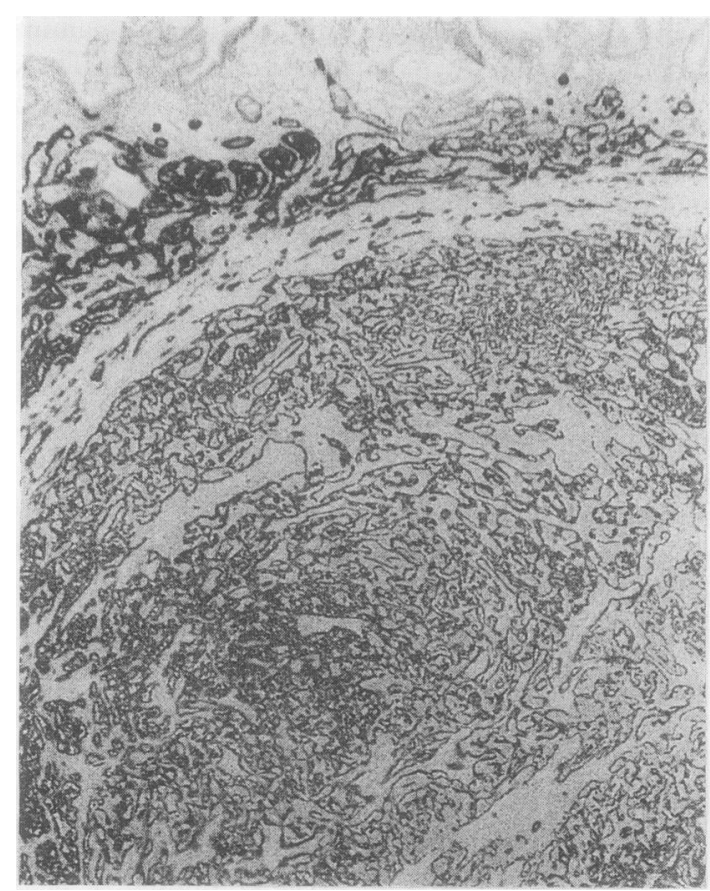

Fig 2 Low power view of large gastric body carcinoid in case 2 showing positive staining for PGP 9.5. Tumour is seen within lamina propria and expands submucosa.

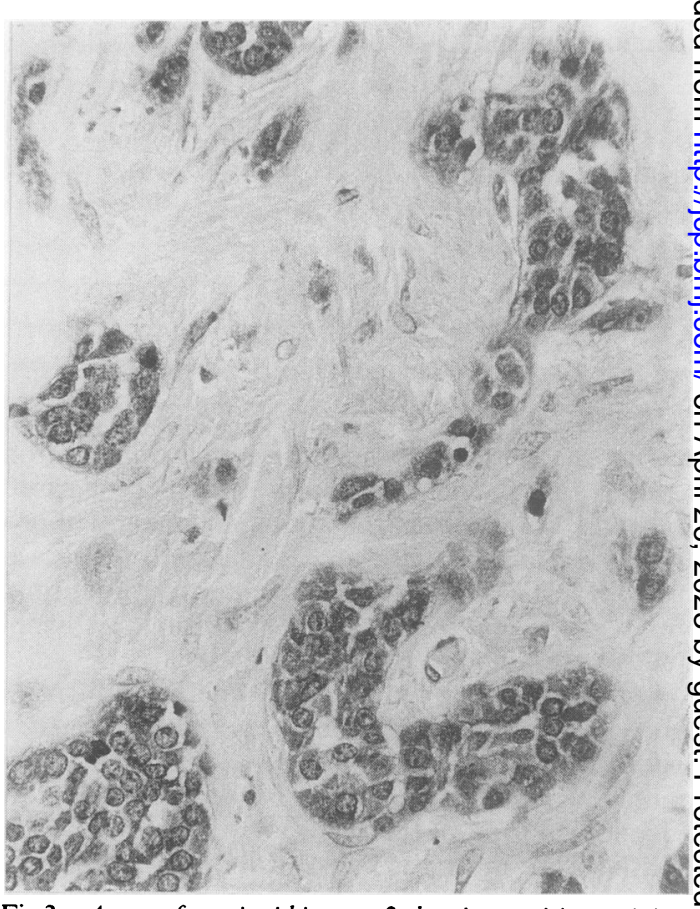

Fig 3 Areas of carcinoid in case 2 showing positive staining for gastrin.

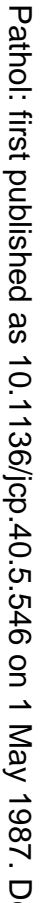

(1) 


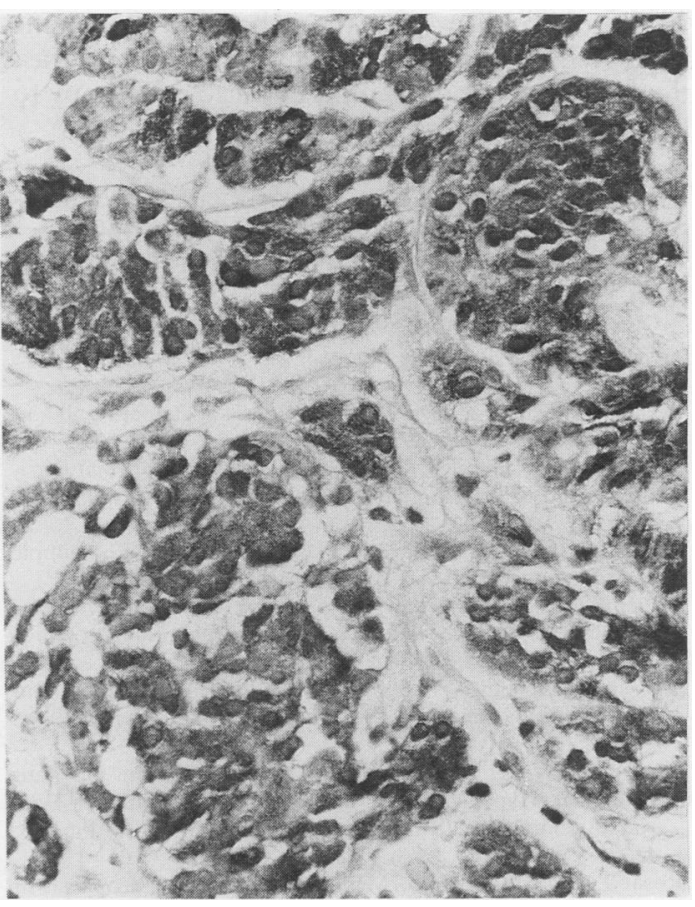

Fig 4 Part of small polypoid carcinoid tumour in case I showing positive staining for PP.

one area. The interpretation was that of parathyroid adenoma.

During neck and mediastinal exploration in case 3 three normal sized parathyroid glands were located and biopsied, and during the course of the operation a $3 \mathrm{~cm}$ portion of thyroid gland was removed from its lower pole. On cut surface this showed an encapsulated nodule measuring $1 \mathrm{~cm}$ in diameter. Histological examination showed the features of a parathyroid adenoma composed of a solid aggregate of chief cells within thyroid. Immunohistochemical stains for calcitonin were negative, excluding the possibility that the tumour was a medullary carcinoma of thyroid. Parathyroid tissue with a normal complement of interspersed adipocytes was seen in sections of the three parathyroid gland biopsy specimens.

\section{Discussion}

The clinical and pathological features of these cases are typically those of a pluriglandular syndrome. Two of our patients showed multiple small polypoid carcinoids of the non-antral stomach in conjunction with a parathyroid adenoma in one and parathyroid hyperplasia in the other. A third patient had a large metastasising carcinoid arising in the gastric body. Immunohistochemical stains showed multifocal neuroendocrine cell proliferations in the gastric mucosa adjacent to the main tumour. Three years after removal of a parathyroid adenoma this patient became hypercalcaemic again and is under further investigation. A positive family history of endocrine hyperplasia and neoplasia was established in one of our cases.

Carcinoid tumours of the stomach are rare, constituting only $3 \%$ of all gut carcinoids, ${ }^{1112}$ and they account for $0.3 \%$ of all stomach tumours. ${ }^{11}$ Patients with pernicious anaemia are reported to have an increased risk of developing gastric carcinoids. ${ }^{13-15}$ In such patients the carcinoid tumours are often small, polypoid, and multiple and affect the fundus and body, as was the case in two of our patients. One of these patients had pernicious anaemia and there was severe atrophy of the non-antral stomach mucosa. Chronic non-antral gastritis without atrophy was seen in the other patient but tests for pernicious anaemia proved negative. In all three of our cases the gastric body mucosa showed focal severe small intestinal metaplasia.

Multiple gastric carcinoid tumours, especially those associated with pernicious anaemia, are slow growing tumours and metastasis occurs late in the course of the disease. ${ }^{13-17}$ Cases 1 and 3 with multiple carcinoidosis of the stomach were followed up for two and seven years, respectively, without clinical evidence of metastatic disease.

Recently we reviewed a case of multiple small gastric carcinoids in pernicious anaemia (by courtesy of Professor M Stolte, Bayreuth, West Germany) where the patient had refused surgery after gastric carcinoid was diagnosed 12 years ago and is still free of identifiable metastases at the time of writing. The metastatic case presented in the present paper had a large $2 \mathrm{~cm}$ primary tumour which had penetrated and expanded the entire submucosa. An association between size and malignant potential of gastrointestinal carcinoids has been reported previously. ${ }^{18}$ Our case also showed occasional tumour cell mitoses in the primary lesion that were not detected in the biopsy material of the two other cases.

The term "carcinoid" encompasses morphologically similar but functionally heterogeneous neoplasms. ${ }^{19}$ The histogenesis and pathogenesis of these tumours have been the subject of recurrent debate. ${ }^{17}$ Conventional opinion holds that gastrointestinal carcinoids arise from enteroendocrine cells within crypt or glandular epithelium. Recently, however, it has been suggested that such neoplasms may also originate from neuroendocrine cells within a neural plexus in the lamina propria. ${ }^{81030}$

Most investigators believe that the fundamental mechanism in the induction of gastric carcinoids is the trophic effect on the enterochromaffin-like cells of 
high values of gastrin, ${ }^{21}$ which in most instances is said to be produced by hyperplastic antral $G$ cells. In pernicious anaemia ${ }^{17}$ and animals subjected to long term treatment with potent $\mathbf{H}_{2}$ blockers ${ }^{22}$ hypergastrinaemia is said to occur in response to profound achlorhydria: one of our patients had pernicious anaemia. In all three patients the serum gastrin concentrations were raised and gastrin immunoreactivity was found within the carcinoids. Under certain conditions raised serum gastrin concentration may exert a trophic effect on tissues other than the oxyntic mucosa.

Conversely, hyperparathyroidism has been shown to produce antral $\mathrm{G}$ cell hyperplasia ${ }^{2324}$ and a trophic effect of raised serum calcium concentrations on $\mathrm{G}$ cell has been proposed ${ }^{24}$ The parathyroid origin of gastrin is a further possibility. A case of hyperparathyroidism and hypergastrinaemia with multiple endocrine adenopathy has been reported. ${ }^{25}$ The hypergastrinaemia was corrected in this patient after parathyroidectomy and gastrin was histochemically shown in the parathyroid tissue; but in a recent review $^{26}$ it has been suggested that hypergastrinaemia may not be the sole or even the most important factor in the pathogenesis of tumours of enterochromaffinlike cells. Other humoral and neuronal stimuli were also found to be important for the trophic control of enterochromaffin-like cells.

Samaan et al found raised serum calcitonin concentrations in three patients with the rare association of hyperparathyroidism and ileal carcinoids ${ }^{27}$ and they suggested that hyperparathyroidism in these patients was primary, inducing calcitonin producing carcinoids. Serum calcitonin concentration was normal in our patients and we were unable to show calcitonin within the carcinoids by immunohistochemical methods. Such studies showed PP immunoreactive areas within the gastric carcinoids in cases 1 and 3 . This is in keeping with the raised serum PP values found in both patients. Normally high numbers of PP cells are only found in a segment of pancreas derived from its ventral primordium. ${ }^{28}$ Pure PP producing pancreatic tumours of the pancreas are rare, and extrapancreatic PP positive endocrine tumours have been reported on only three occasions ${ }^{29}$ to our knowledge. Notably, the pancreatic tumour of the brother of case 1 also showed PP positivity. Although $P P$ is thought to modulate the secretion of pancreatic enzymes and to cause gall bladder contraction, ${ }^{30}$ its physiological role is still unclear.

In summary, we suggest that carcinoid tumours of the stomach can occur in association with hyperparathyroidism as part of a pluriglandular syndrome. The pathogenetic mechanisms of this relation are still unclear. Patients with gastrointestinal carcinoid tumours and their families should be evaluated for hyperparathyroidism. On the other hand, patients 0 with hyperparathyroidism presenting with upper gas- $\vec{F}$ trointestinal symptoms should undergo endoscopy to 으․ rule out gastric carcinoid tumours.

We thank Dr RJ Thompson, department of biochemistry, Addenbrooke's Hospital, Cambridge, for gener- $\frac{\bar{\sigma}}{\bar{\omega}}$ ous supply of antihuman NSE and PGP 9.5, and $\overrightarrow{\widetilde{\sigma}}$ Miss E Moss for technical help.

\section{References}

1 Wermer P. Genetic aspects of adenomatosis of endocrine glands. Am J Med 1954;16:363-71.

2 Williams ED, Celestin LR. The association of bronchial carcinoids and pluriglandular adenomatosis. Thorax 1962;17:? $120-7$.

3 Snyder N III, Murphy TS, Deiss WP. Five families with multiple $\overrightarrow{0}$ endocrine adenomatosis. Ann Intern Med 1972;76:53-8.

4 Fisher ER, Hicks J. Further pathologic observation on the syn-

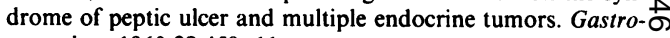
enterology 1960;38:458-66.

5 Gerber BC, Shields TW. Simultaneous duodenal carcinoid and non-beta cell tumor of the pancreas. Arch Surg 1960;81: 379-88.

6 Schmid M, Wenzl H, Uehlinger E. Inselzell-Adenom des Pan kreas mit Hypoglykaemie, kombiniert mit multiplen Kar- $\overrightarrow{-}$ zinoidtumoren des Ileum. Schweiz Med Wochenschr 1963;93:@ 444-6.

7 Rosai J, Higa E, Davie J. Mediastinal endocrine neoplasm in patients with multiple endocrine adenomatosis. A previouslyo unrecognised association. Cancer 1972;29:1075-83.

8 Rode J, Dhillon AP, Papadaki L, Griffiths D. Neurosecretory cells of the lamina propria of the appendix and their possible relationship to carcinoids. Histopathology 1982;6:69-79.

9 Rode J, Dhillon AP, Doran JF, Jackson P, Thompson RJ. PGP 9.5, a new marker for human neuroendocrine tumours. Histo- $\overrightarrow{\vec{O}}$ pathology 1985;9:147-58.

10 Rode J, Dhillon AP, Papadaki L, et al. Pernicious anaemia and mucosal endocrine proliferations of the non-antral stomach. Gut 1986;27:789-98.

11 Godwin JD. Carcinoid tumors: an analysis of 2837 cases. Cancer 1975;36:560-9.

12 McDonald RA. A study of 356 carcinoids of the gastrointestinal tract. Am J Med 1956;21:867-8.

13 Morgan JE, Kaiser CW, Johnson W, et al. Gastric carcinoid (gastrinoma) associated with achlorhydria (pernicious anaemia). Cancer 1983;51:2332-40.

14 Wilander E, El-Salhy M, Pitkanen P. Histopathology of gastric $\mathrm{O}$ carcinoids: a survey of 42 cases. Histopathology 1984;8:183-93.

15 Carney JA, Go VLW, Fairbanks VF, Moore SB, Alport EC, Nora FE. The syndrome of gastric argyrophil carcinoid tumors and non antral gastric atrophy. Ann Intern Med 1983;99:761-6. N

16 Hodges JR, Isaacson P, Wright R. Diffuse enterochromaffin-like ? (ECL) cell hyperplasia and multiple gastric carcinoids: a com- N plication of pernicious anaemia. Gut 1981;22:237-41.

17 Harvey RF, Davidson CM, Bradshaw MJ, Wilkinson SP. Multi- $\omega$ focal carcinoid tumours, achlorhydria and hypergastrinaemia. Lancet 1985;i:951-8.

18 Hajdu SI, Winawar SJ, Myers WPL. Carcinoid tumors. A study of 204 cases. Am J Clin Pathol 1974:61:521-8.

19 Editorial. Carcinoid tumors. Changing concepts and new perspectives. Am J Surg Pathol 1984;8:295-300.

20 Auböck L, Höfler $H$. Extraepithelial intraneural endocrine cells as starting-points for gastrointestinal carcinoids. Virchows $\mathbb{D}$ Arch (Pathol Anat) 1983;401:17-33.

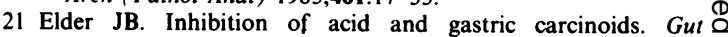
1985;26:1279-83. 
22 Poynter D, Pick CR, Harcourt RA, et al. Association of long lasting unsurmountable histamine $\mathrm{H}_{2}$ blockade and gastric carcinoid tumour in the rat. Gut 1985;26:1284-95.

23 Polak JM, Bussolati G, Pearse AGE. Cytochemical, immunofluorescence and ultrastructural investigation on the antral G cells in hyperparathyroidisam. Virchows Arch (Cell Pathol) 1971;9:187-97.

24 Creutzfeld W, Arnold R, Creutzfeld C, Feurle G, Ketterer H. Gastrin and G-cells in the antral mucosa of patients with pernicious anaemia, acromegaly and hyperparathyroidism and in Zollinger-Ellison tumour of the pancreas. Europ J Clin Invest 1971;1:461-79.

25 Cassar J, Polak JM, Cooke WM. Possible parathyroid origin of gastrin in a patient with multiple endocrine adenopathy type $I$. Br J Surg 1975;62:313-6.

26 Håkonson R, Ekelund M, Sundler F. Activation and proliferation of gastric endocrine cells. In: Falkmer S, Hakonson R, Sundler F, eds. Evolution and tumour pathology of the neuroendocrine system. Amsterdam: Elsevier, 1984:371-98.
27 Samaan NA, Hickey RC, Bedner TD, Ibanez ML. Hyperparathyroidism and carcinoid tumor. Ann Intern Med 1975;82: 205-7.

28 Dhillon AP, Rode J, Lowes JR, Cotton PB. Morphological distinction of ventral and dorsal anlagen in adult pancreas. $J$ Pathol 1985;146:263A-4.

29 Solt J, Kádas I, Polak JM, et al. A pancreatic-polypeptide producing tumor of the stomach. Cancer 1984;54:1101-4.

30 Adrian TA, Greenberger GR, Bloom SR. Action of pancreatic polypeptide in man. In: Bloom SR, Polak JM, eds. Gut hormones. Edinburgh: Churchill Livingstone, 1981:206-12.

Requests for reprints to: Dr J Rode, Bland-Sutton Institute of Pathology, The Middlesex Hospital Medical School, Mortimer Street, London W1P 7PN, England. 